\title{
Revisiting the neuropsychiatry of Huntington's disease
}

\author{
Antonio Lucio Teixeira ${ }^{1,2}$, Leonardo Cruz de Souza ${ }^{1}$, Natalia Pessoa Rocha ${ }^{1,2}$, \\ Erin Furr-Stimming ${ }^{3}$, Edward C. Lauterbach ${ }^{4}$
}

\begin{abstract}
Huntington's disease (HD) is an autosomal dominant neurodegenerative disease classified under the choreas. Besides motor symptoms, HD is marked by cognitive and behavioral symptoms, impacting patients' functional capacity. The progression of cognitive impairment and neuropsychiatric symptoms occur in parallel with neurodegeneration. The nature of these symptoms is very dynamic, and the major clinical challenges include executive dysfunction, apathy, depression and irritability. Herein, we provide a focused updated review on the cognitive and psychiatric features of HD.
\end{abstract} Key words: Huntington's disease, neuropsychiatry, cognition, behavior.

\section{REVISITANDO A NEUROPSIQUIATRIA DA DOENÇA DE HUNTINGTON}

RESUMO. A doença de Huntington (DH) é uma doença neurodegenerativa autossômica dominante classificada entre as coreias. Além de sintomas motores, a DH é caracterizada por sintomas cognitivos e comportamentais que impactam na capacidade funcional dos pacientes. A progressão dos sintomas neuropsiquiátricos e déficits cognitivos ocorre paralelamente à neurodegeneração. A natureza desses sintomas é muito dinâmica, sendo que os desafios clínicos mais comuns incluem disfunção executiva, apatia, depressão e irritabilidade. 0 presente artigo apresenta uma revisão atualizada sobre as manifestações cognitivas e psiquiátricas da $\mathrm{DH}$.

Palavras-chave: doença de Huntington, neuropsiquiatria, cognição, comportamento.

\section{INTRODUCTION}

Tuntington's disease (HD) is an autoso1 mal dominant neurodegenerative disease caused by the expansion of CAG repeats in the exon 1 of the HTT gene at the short arm of chromosome four (4p16.9), responsible for the synthesis of the huntingtin protein. The mutant gene seems to confer a toxic gain of function, leading to characteristic neuropathological changes, including accumulation of nuclear and cytoplasmic inclusions of mutant huntingtin in neurons, with prominent degeneration of the caudate and putamen. ${ }^{1}$

HD is traditionally classified under the choreas, i.e. involuntary movement disorders characterized by non-rhythmic and random muscle contractions that can affect any part of the body. ${ }^{2}$ Before the advent of genetic testing, HD was diagnosed by the presence of chorea in the context of a family history of the disease. Indeed, chorea is one the earliest motor manifestations of typical HD. However, chorea is a poor marker of disease progression, stabilizing and/or fading away in late stages of HD. Moreover, patients with earlyonset HD, i.e. before 21 years of age, tend to develop other motor symptoms, and may not have chorea. ${ }^{3}$ These symptoms include bradykinesia, rigidity, dystonia and motor incoordination.

Besides motor symptoms, HD is marked

This study was conducted at the Laboratorio Interdisciplinar de Investigação Médica, Faculdade de Medicina, Universidade Federal de Minas Gerais, Belo Horizonte MG, Brazil.

${ }^{1}$ Laboratorio Interdisciplinar de Investigação Médica, Faculdade de Medicina, Universidade Federal de Minas Gerais, Belo Horizonte MG, Brazil. ${ }^{2}$ Neuropsychiatry Program, Department of Psychiatry and Behavioral Sciences, McGovern Medical School, University of Texas Health Science Center at Houston, Houston, TX. ${ }^{3}$ Department of Neurology, McGovern Medical School, University of Texas Health Science Center at Houston, Houston, TX. ${ }^{4}$ Department of Psychiatry and Behavioral Sciences, Mercer University School of Medicine, Macon, GA.

Antonio Lucio Teixeira. Department of Psychiatry and Behavioral Sciences McGovern Medical School. The University of Texas Health Science Center at Houston 1941 East Road, Houston - TX 77054 - USA BBSB 3140. E-mail: altexr@gmail.com

Disclosure: The authors report no conflicts of interest.

Received April 28, 2016. Accepted in final form July 20, 2016 
by cognitive and behavioral symptoms. Non-chorea motor and cognitive changes present with a steady progression, impacting patients' functional capacity. Psychiatric symptoms are also very common, but have a more unpredictable course, sometimes flaring or remitting unexpectedly. ${ }^{4}$ The objective of the current manuscript is to provide a focused updated review on the cognitive and psychiatric features of HD.

\section{COGNITIVE IMPAIRMENT}

The degenerative nature of HD leads to gradually progressive cognitive impairment. Due to the relative preservation of memory at disease onset, cognitive decline in HD has been classically characterized as the "subcortical type". 5 The term "subcortical dementia" was proposed by Albert in 1974 to refer to the cognitive impairment observed in patients with progressive supranuclear palsy, characterized by executive deficits (mainly slow processing speed and attentional disorders) and behavioral changes (such as apathy), without any evidence of "true cortical" involvement (aphasia, apraxia, agnosia). ${ }^{6,7}$ Since Albert's initial proposal, "subcortical dementia" has been used to describe the cognitive profile of other neurological disorders, including Parkinson's disease and HD. Although this concept is still employed to assign the neuropsychiatric disorders of HD, the concept of "subcortical dementia" has been challenged. Indeed, the advent of modern neuroimaging techniques and new methods of neuropsychological assessment have demonstrated evidence of "cortical" deficits due to subcortical lesions, in the absence of cortical damage. ${ }^{8,9}$ More specifically, it has been increasingly recognized that the striatum has a prominent role in the modulation of complex cognitive abilities in different neurological diseases, including HD. ${ }^{10}$

Executive deficits are the main neuropsychological features of HD, even at pre-manifest and stages of the disease. ${ }^{10,11}$ Patients typically have attentional complaints that are generally referred as "memory disorders". The cognitive exam discloses low performance in working memory, flexibility and planning. ${ }^{11-14}$ These executive deficits are more severe than those observed in Alzheimer's disease at the same disease duration. Adaptive behavior and rule learning are also frequently impaired in HD. In line with these aforementioned difficulties, patients with HD generally have low performance on the Wisconsin Card Sorting Test, Trail Making Test and Spans. There is also impairment in planning and problem-solving abilities, as demonstrated by difficulties on the London Tower test. ${ }^{11-14}$
Memory complaints are frequent among HD patients. Besides complaints, an objective memory deficit is regularly demonstrated in HD, characterized by a low immediate and delayed recall performance on both verbal and visual memory tests. It seems that episodic memory impairment in HD is mainly due to a retrieval deficit, due to an impaired ability to activate strategies needed for retrieving stored information. ${ }^{15-17}$ This recall impairment may result from registration and/or retrieval deficits linked to subcortical-frontal dysfunction, rather than from a storage problem due to damage in medial-temporal lobe structures, as seen in Alzheimer's disease. Indeed, HD and Alzheimer's disease differ in their episodic memory profile. While there are recall deficits in both diseases, patients with HD benefit from semantic cueing, which is not the case for patients with Alzheimer's disease. Recall performance in HD is generally improved, or even normalized, with the use of semantic cueing. ${ }^{15,16}$ Recognition is also usually preserved in HD, while it is impaired in Alzheimer's disease.

Language impairment is present in HD, with reduced lexical fluency being the most reported finding. Patients with early stage HD may have difficulties in rule application in different domains, such as verbal conjugation and syntax comprehension. ${ }^{18} \mathrm{~A}$ Brazilian study investigated 23 patients with HD and found low performance on repetition, oral agility and comprehension in both oral and reading modalities. ${ }^{19}$ Besides language deficits, communication abilities of HD patients can be also impaired by dysarthria and involuntary oromandibular movements.

More recently, it has been demonstrated that social cognition is affected in HD. For instance, the identification of negative facial emotions (anger, disgust, sadness and fear) is compromised early in HD. ${ }^{20}$ There is also emerging evidence that patients with HD have deficits in sarcasm detection and in both affective and cognitive aspects of theory of mind, even at pre-manifest stages of the disease. ${ }^{21-23}$

Taken together, the recent advances in the neuropsychological investigation of HD have demonstrated evidence of cognitive deficits beyond those assigned to the concept of "subcortical dementia".

It is worth emphasizing the dynamic nature of cognitive changes in HD. Moreover, the rates of cognitive decline seem to differ with disease progression. The rate of change tends to accelerate with disease progression, particularly after the critical point of moving from undiagnosed to diagnosed HD. ${ }^{24}$ From a neurobiological standpoint, it has been proposed that these changes may be the clinical correlate of the activation of intracel- 
lular cascades or pathways beyond the accumulation of misfolded huntingtin. ${ }^{25}$

Neuroimaging studies have shown a robust correlation between cognitive performance and imaging parameters. For instance, caudate volume significantly correlated with different executive function tests in patients with HD. ${ }^{26}$ Using diffusion tensor imaging, Delmaire et al. (2013) reported correlation between mean diffusivity in the anterior part of the putamen and the caudate nucleus, and executive functioning as assessed by the Trail Making Test, Part B. ${ }^{27}$ It is important to mention that imaging measures, notably striatal atrophy, have shown the largest effect size for tracking HD progression so far. ${ }^{28}$

Higher cognitive reserve was significantly associated with a slower rate of change in executive function (Trail Making Test, Part B) and slower rate of volume loss in caudate and putamen for HD mutation carriers estimated to be closest to motor symptom onset, i.e. 'phenoconversion'. ${ }^{29}$ However, cognitive reserve modified the rate of cognitive decline only in patients at phenoconversion, and not among those HD mutation carriers estimated to be distant from motor onset. These results corroborate the hypothesis of disease acceleration at the time of 'phenoconversion', and striatal atrophy as a pivotal biomarker in HD.

\section{BEHAVIORAL OR NEUROPSYCHIATRIC SYMPTOMS}

Systematic studies on behavioral and psychopathological issues of HD were scarce until the 2000s when a growing volume of literature emerged. Older studies reported that personality changes were found in $70 \%$ of patients with $\mathrm{HD},{ }^{30}$ but most of these studies lacked reliable diagnostic tools, and did not follow current classification systems (i.e. the Diagnostic and Statistical Manual of Mental Disorders or the International Classification of Disorders). ${ }^{5}$ The relationship between CAG trinucleotide repeat length and psychiatric manifestations of HD has also been investigated in relatively small samples with contradicting results. ${ }^{31,32}$

It is misleading to regard behavioral and/or psychiatric symptoms in HD as a homogeneous and/or static entity. Independent groups identified clusters of behavioral symptoms in HD. Based on the Problem Behaviors Assessment in HD, three clusters of symptoms were identified: apathy, depression, and irritability. ${ }^{33,34}$ Using data from the European Huntington's Disease Network REGISTRY that assessed the Unified HD Rating Scale in almost 2,000 HD mutation carriers, Rickards et al. (2011) identified four distinct behavioral patterns: depression, irritability/aggression, psychosis, and dysex- ecutive. ${ }^{35}$ The latter included apathy, obsessive and compulsive behaviors. The Unified HD Rating Scale covers 11 psychiatric symptoms, including anxiety, depressed mood, irritability, perseveration, apathy, delusions and hallucinations that are individually scored according to their severity and frequency. ${ }^{35}$

Based on the analysis of the same REGISTRY database, it was reported that less than $30 \%$ of mutation carriers had no neuropsychiatric symptoms in the month prior to study evaluation..$^{36}$ Apathy was reported by $47.4 \%$ of subjects, while depression and irritability/ aggression occurred in $42.1 \%$ and $38.6 \%$, respectively. Moderate-to-severe apathy affected $28.1 \%$ of subjects, while moderate-to-severe depression occurred in $12.7 \%$. Obsessive-compulsive behaviors and psychosis occurred in $25.8 \%$ and $4.1 \%$ of subjects, respectively. These neuropsychiatric symptoms were present in all stages of $\mathrm{HD}$, but tended to be more frequent in late or advanced stages of the disease. Among the five neuropsychiatric syndromes assessed in the study, i.e. depression, irritability/aggression, psychosis, apathy, and obsessivecompulsive behaviors, apathy showed the strongest association with disease progression. The prevalence of moderate-to-severe apathy increased with disease stage from $11 \%$ in stage 1 to $54.6 \%$ in stages 4 and $5 .{ }^{36}$

Important lessons can be extracted from the REGISTRY study: i) neuropsychiatric syndromes are very common in HD, already in the pre-manifest stage, but not all patients exhibit severe symptoms; ii) the prevalence of neuropsychiatric syndromes tend to increase with disease progression; iii) apathy is the best behavioral or neuropsychiatric correlate of disease progression in HD. More recently, the PREDICT-HD study, that followed a cohort of over 1,000 HD mutation carriers for up to ten years, confirmed that neuropsychiatric manifestations develop more often than previously thought in the HD pre-manifest stage, and increase with progression of disease severity. ${ }^{37}$ Other studies, including the longitudinal study TRACK-HD, confirmed apathy as an early manifestation and a core neuropsychiatric feature of $\mathrm{HD}$ that correlated with its progression. ${ }^{24,38}$ Interestingly, apathy is also appointed as the best behavioral predictor of Alzheimer's disease progression. ${ }^{39}$

Depressive disorders are the second-most-common neuropsychiatric problem in HD. In clinical practice, the best discriminators of depression in HD are affective symptoms (i.e. sadness, loss of interest, guilt and suicidality) in contrast with somatic symptoms, such as impairment of appetite, sleep, and psychomotor retardation, that may overlap non-psychiatric problems. ${ }^{35}$ Factors potentially associated with depression in HD 
include female sex, and a positive history of depression as the main correlate in the REGISTRY study (Odds ratio, $\mathrm{OR}=5.57$ ). It is tempting to speculate whether this positive psychiatric history for depression represents very early symptoms related to HD pathological changes instead of a traditional risk factor. Besides this, the role played by psychosocial factors in HD associated depression remains to be better defined. Depressed mood is a very important predictor of suicidal ideation that affects approximately $10 \%$ of HD mutation carriers. ${ }^{40}$ Older studies reported that $25 \%$ of patients had at least one suicide attempt throughout the disease, and suicide was the ultimate cause of death in up to $10 \%$ of patients. ${ }^{41}$

Older studies also reported schizophrenia-like psychosis in a significant number of patients with HD. ${ }^{42}$ Psychiatrists even believed that a patient with schizophrenia-like psychosis might later be diagnosed with HD. ${ }^{5}$ In fact, psychotic disorders occur in few patients with $\mathrm{HD}$, with a prevalence of below 5\%. ${ }^{36}$ Psychosis usually develops in more advanced phases of disease and/or in individuals with a longer duration of disease.

Irritability and aggression are frequent behavioral symptoms in HD. In the REGISTRY and TRACK-HD studies, these symptoms were also associated with functional decline in HD, but to a lesser extent than apathy. ${ }^{24,36}$ Accordingly, along with apathy, they can be regarded as signs of frontal lobe dysfunction in HD. Other behavioral problems, such as drug abuse, sleep disorders and hyper-sexuality, can be of clinical concern in HD.

\section{TREATMENT}

Based on the multiple pathophysiological mechanisms implicated in HD, different pharmacological strategies have been evaluated in pre-clinical and clinical studies in HD. ${ }^{28,43,44}$ However, to date there are no disease-modifying strategies available for HD. Promising strategies in pre-clinical models were not confirmed in clinical trials. For instance, latrepirdine, a molecule originally developed as an oral antihistaminic and later shown to stabilize mitochondrial membranes and function, failed to influence cognition and global function in a randomized, double-blind, placebo-controlled trial comprising 403 patients with mild to moderate HD. ${ }^{45}$ Further molecules acting on mitochondrial function or oxidative stress (e.g. coenzyme Q10), and other biological processes such as neuroinflammation (minocycline) did not indicate evidence of efficacy in halting or slowing down HD progression. ${ }^{46,47}$ There is a great hope that genetic-based interventions, such as RNA interference and antisense oligonucleotides, will change this scenario. ${ }^{44}$
In clinical practice, treatment is directed to target symptoms and/or syndromes, such as chorea, irritability/aggression, depression and cognitive decline. In its guidelines for the management of chorea in HD, the American Academy of Neurology recommends the use of tetrabenazine, amantadine and riluzole. ${ }^{48}$ However, tetrabenazine, a specific inhibitor of vesicular monoamine transporter (VMAT2), is the only FDA-drug approved for chorea in patients with HD. ${ }^{49,50}$ There is also preclinical evidence of neuroprotective effects of tetrabenazine in a HD model. ${ }^{51}$ The adverse effects with tetrabenazine include somnolence, depressed mood, agitation and akathisia. Considering the high frequency of depressive symptoms in HD and their potential exacerbation with tetrabenazine, patients taking this drug must be closely monitored for depression and suicidal ideation. In this latter context, amantadine and riluzole could be better therapeutic options.

Behavioral and cognitive interventions are warranted for managing neuropsychiatric and cognitive symptoms, but their evidence of efficacy is very limited. ${ }^{52,53}$ Pharmacological strategies can improve symptom management, but again formal evidence is lacking. Treatment recommendations for neuropsychiatric symptoms are based on expert opinion surveys, open label and/or small controlled studies. ${ }^{53-55}$ Therefore, this is an area with urgent need of research, especially taking into consideration that some strategies may have broad therapeutic and/or deleterious potentials. The antidepressants, for instance, may be theoretically effective in the treatment of mood symptoms, and there is evidence of prevention of neurodegenerative changes characteristic of HD, awaiting clinical confirmation. ${ }^{56}$ Conversely, antipsychotics or anti-dopaminergic drugs that can be used for the treatment of psychotic phenomena, irritability/agitation or even chorea, may lead to more advanced and rapidly progressing HD. ${ }^{57}$

Small controlled studies with atomoxetine, donepezil, and rivastigmine, and open trials with memantine did not find positive effects of these drugs on the cognition of patients with HD. ${ }^{58-62}$ Recently, a 26-week, randomized, double-blind, placebo-controlled trial with 109 early-stage to mid-stage HD patients did not show improvement of a composite of cognitive measures in patients assigned to PBT2, a compound that might reduce metal-induced aggregation of mutant huntingtin. ${ }^{63}$ However, compared with the placebo group, the Trail Making Test Part B score improved between baseline and 26 weeks in the PBT2 $250 \mathrm{mg}$ group, but not in the $100 \mathrm{mg}$ group. This potential benefit in executive function must be confirmed in independent studies. It 
must also be evaluated whether this cognitive improvement translates into better global functioning.

\section{CONCLUSION}

Neuropsychiatric and cognitive symptoms are integral components of the clinical spectrum of HD, reflecting pathological changes in the striatum and cortical regions. In parallel with neurodegeneration, there is progression of cognitive impairment and neuropsychiatric symptoms, mainly apathy and irritability/aggression that can be regarded as signs of frontal lobe dysfunction.

There are no disease-modifying strategies for HD, and current treatment is directed to target symptoms, especially motor and behavioral symptoms. The available evi- dence for the treatment of neuropsychiatric and cognitive manifestations in $\mathrm{HD}$ is very limited, and studies to date have failed to show convincing results. Accordingly, there is a large venue for therapeutic investigation in HD.

Author contribution. Dr. Teixeira, Dr. Rocha and Dr. Lauterbach were responsible for conception and design of the current review. Dr. Teixeira, Dr. Souza and Dr. Furr-Stimming were responsible for studies selection, analysis and interpretation. Dr. Teixeira wrote the first draft of the manuscript that was critically revised by all authors. All authors approved the final version of the manuscript.

\section{REFERENCES}

1. Walker FO. Huntington's disease. Lancet. 2007;369(9557):218-28.

2. Cardoso F. Huntington disease and other choreas. Neurol Clin. 2009;27(3):719-36

3. Mahant N, McCusker EA, Byth K, Graham S. Huntington Study Group. Huntington's disease: clinical correlates of disability and progression. Neurology. 2003;61(8):1085-92.

4. Dorsey ER, Beck CA, Darwin K, et al. Natural history of Huntington disease. JAMA Neurol. 2013;70(12):1520-30.

5. Naarding P, Kremer HP, Zitman FG. Huntington's disease: a review of the literature on prevalence and treatment of neuropsychiatric phenomena. Eur Psychiatry. 2001;16(8):439-45

6. Albert ML, Feldman RG, Willis AL. The 'subcortical dementia' of progressive supranuclear palsy. J Neurol Neurosurg Psychiatry. 1974; 37(2):121-30.

7. Kertesz A, McMonagle P. Behavior and cognition in corticobasal degeneration and progressive supranuclear palsy. I Neurol Sci. 2010;289(1-2):138-43.

8. Catani M, Dell'acqua F, Bizzi A, Forkel SJ, Williams SC, Simmons A, Murphy DG. Thiebaut de Schotten M. Beyond cortical localization in clinico-anatomical correlation. Cortex. 2012;48(10):1262-87.

9. Mesulam M. Imaging connectivity in the human cerebral cortex: the next frontier? Ann Neurol. 2005;57(1):5-7.

10. O'Callaghan C, Bertoux M, Hornberger M. Beyond and below the cortex: the contribution of striatal dysfunction to cognition and behaviour in neurodegeneration. J Neurol Neurosurg Psychiatry. 2014;85(4):371-8.

11. Paulsen JS. Cognitive impairment in Huntington disease: diagnosis and treatment. Curr Neurol Neurosci Rep. 2011;11(5):474-83.

12. Peavy GM, Jacobson MW, Goldstein JL, Hamilton JM, Kane A, Gamst AC, et al. Cognitive and functional decline in Huntington's disease: dementia criteria revisited. Mov Disord. 2010;25(9):1163-9.

13. Stout JC, Paulsen JS, Queller S, Solomon AC, Whitlock KB, Campbell $\mathrm{JC}$, et al. Neurocognitive signs in prodromal Huntington disease. Neuropsychology. 2011;25(1):1-14

14. Stout JC, Jones R, Labuschagne I, O'Regan AM, Say MJ, Dumas EM, et al. Evaluation of longitudinal 12 and 24 month cognitive outcomes in premanifest and earlyHuntington's disease. J Neurol Neurosurg Psychiatry. 2012l;83(7):687-94.

15. Pillon B, Deweer B, Agid Y, Dubois B. Explicit memory in Alzheimer's, Huntington's, and Parkinson's diseases. Arch Neurol. 1993;50(4):374-9.

16. Pillon B, Blin J, Vidailhet M, Deweer B, Sirigu A, Dubois B, Agid Y. The neuropsychological pattern of corticobasal degeneration: comparison with progressive supranuclear palsy and Alzheimer's disease. Neurology. 1995;45(8):1477-83

17. Solomon AC, Stout JC, Johnson SA, Langbehn DR, Aylward EH, Brandt $J$, et al. Predict-HD investigators of the Huntington Study Group. Verbal episodic memory declines prior to diagnosis in Huntington's disease. Neuropsychologia. 2007;45(8):1767-76.

18. Teichmann M, Dupoux E, Kouider S, Brugières P, Boissé MF, Baudic S, et al. The role of the striatum in rule application: the model of Huntington's disease at early stage. Brain. 2005;128(Pt 5):1155-67.

19. Azambuja MJ, Radanovic M, Haddad MS, Adda CC, Barbosa ER, Mansur LL. Language impairment in Huntington's disease. Arq Neuropsiquiatr. 2012;70(6):410-5.

20. Johnson SA, Stout JC, Solomon AC, Langbehn DR, Aylward EH, Cruce $\mathrm{CB}$, et al. Predict-HD Investigators of the Huntington Study Group. Beyond disgust: impaired recognition of negative emotions prior to diagnosis in Huntington's disease. Brain. 20071;130(Pt 7):1732-44.

21. Allain P, Havet-Thomassin V, Verny C, Gohier B, Lancelot C, Besnard J, et al. Evidence for deficits on different components of theory of mind in Huntington's disease. Neuropsychology. 2011;25(6):741-51.

22. Eddy CM, Rickards HE. Theory of mind can be impaired prior to motor onset in Huntington's disease. Neuropsychology. 2015;29(5):792-8.

23. Larsen IU, Vinther-Jensen T, Gade A, Nielsen JE, Vogel A. Do I misconstrue? Sarcasm detection, emotion recognition, and theory of mind in Huntington disease. Neuropsychology. 2016;30(2):181-9.

24. Tabrizi SJ, Scahill RI, Owen G, Durr A, Leavitt BR, Roos RA, et al. TRACK-HD Investigators. Predictors of phenotypic progression and disease onset in premanifest and early-stage Huntington's disease in the TRACK-HD study: analysis of 36-month observational data. Lancet Neurol. 2013;12(7):637-49.

25. Walker FO. Huntington's disease: the road to progress. Lance Neurol. 2013;12(7):624-5.

26. Peinemann A, Schuller S, Pohl C, Jahn T, Weindl A, Kassubek J. Execu tive dysfunction in early stages of Huntington's disease is associated with striatal and insular atrophy: a neuropsychological and voxel-based morphometric study. J Neurol Sci. 2005;239(1):11-9.

27. Delmaire C, Dumas EM, Sharman MA, van den Bogaard SJ, Valabregue $R$, Jauffret $C$, et al. The structural correlates of functional deficits in early Huntington's disease. Hum Brain Mapp. 2013;34(9):2141-53.

28. Ross CA, Aylward EH, Wild EJ, Langbehn DR, Long JD, Warner JH, et al. Huntington disease: natural history, biomarkers and prospects for therapeutics. Nat Rev Neurol. 2014;10(4):204-16.

29. Bonner-Jackson A, Long JD, Westervelt H, Tremont G, Aylward E, Paulsen JS. PREDICT-HD Investigators and Coordinators of the Huntington Study Group. Cognitive reserve and brain reserve in prodromal Huntington's disease. J Int Neuropsychol Soc. 2013; 19(7): 739-50.

30. Shiwach R. Psychopathology in Huntington's disease patients. Acta Psychiatr Scand. 1994;90(4):241-6.

31. Berrios GE, Wagle AC, Marková IS, Wagle SA, Ho LW, Rubinsztein DC, et al. Psychiatric symptoms and CAG repeats in neurologically asymptomatic Huntington's disease gene carriers. Psychiatry Res. 2001;102(3):217-25.

32. Illarioshkin SN, Igarashi S, Onodera O, Markova ED, Nikolskaya NN, Tanaka $\mathrm{H}$, et al. Trinucleotide repeat length and rate of progression of Huntington's disease. Ann Neurol. 1994;36(4):630-5. 
33. Craufurd D, Thompson JC, Snowden JS. Behavioral changes in Huntington Disease. Neuropsychiatry Neuropsychol Behav Neurol. 2001;14(4):219-26.

34. Kingma EM, van Duijn E, Timman R, van der Mast RC, Roos RA. Behavioural problems in Huntington's disease using the Problem Behaviours Assessment. Gen Hosp Psychiatry. 2008;30(2):155-61.

35. Rickards H, De Souza J, Crooks J, van Walsem MR, van Duijn E, Landwehrmeyer B, et al. European Huntington's Disease Network. Discriminant analysis of Beck Depression Inventory and Hamilton Rating Scale for Depression in Huntington's disease. J Neuropsychiatry Clin Neurosci. 2011;23(4):399-402.

36. van Duijn E, Craufurd D, Hubers AA, Giltay EJ, Bonelli R, Rickards H, et al. European Huntington's Disease Network Behavioural Phenotype Working Group. Neuropsychiatric symptoms in a European Huntington's disease cohort (REGISTRY). J Neurol Neurosurg Psychiatry. 2014; 85(12):1411-8.

37. Epping EA, Kim JI, Craufurd D, Brashers-Krug TM, Anderson KE, McCusker E, et al. PREDICT-HD Investigators and Coordinators of the Huntington Study Group. Longitudinal Psychiatric Symptoms in Prodromal Huntington's Disease: A Decade of Data. Am J Psychiatry. 2016;173(2):184-92.

38. Martinez-Horta S, Perez-Perez J, van Duijn E, Fernandez-Bobadilla R, Carceller M, Pagonabarraga J, et al. Spanish REGISTRY investigators of the European Huntington's Disease Network, Kulisevsky J. Neuropsychiatric symptoms are very common in premanifest and early stage Huntington's Disease. Parkinsonism Relat Disord. 2016;25:58-64.

39. Teixeira AL, Caramelli P. Apathy in Alzheimer's disease. Rev Bras Psiquiatr. 2006;28(3):238-41.

40. Hubers AA, van Duijn E, Roos RA, Craufurd D, Rickards $H$, Bernhard Landwehrmeyer G, et al. REGISTRY investigators of the European Huntington's Disease Network. Suicidal ideation in a European Huntington's disease population. J Affect Disord. 2013;151(1):248-58.

41. Di Maio L, Squitieri F, Napolitano G, Campanella G, Trofatter JA Conneally PM. Suicide risk in Huntington's disease. J Med Genet. 1993; 30(4):293-5.

42. Caine ED, Shoulson I. Psychiatric syndromes in Huntington's disease. Am J Psychiatry. 1983;140(6):728-33.

43. Pidgeon $\mathrm{C} 1$, Rickards $\mathrm{H}$. The pathophysiology and pharmacologica treatment of Huntington disease. Behav Neurol. 2013;26(4):245-53.

44. Wild EJ, Tabrizi SJ. Targets for future clinical trials in Huntington's disease: what's in the pipeline? Mov Disord. 2014;29(11):1434-45.

45. HORIZON Investigators of the Huntington Study Group and European Huntington's Disease Network. A randomized, double-blind, placebocontrolled study of latrepirdine in patients with mild to moderate Huntington disease. JAMA Neurol. 2013;70(1):25-33.

46. Huntington Study Group. A randomized, placebo-controlled trial of coenzyme Q10 and remacemide in Huntington's disease. Neurology. 2001;57(3):397-404.
47. Huntington Study Group DOMINO Investigators. A futility study of minocycline in Huntington's disease. Mov Disord. 2010;25(13):2219-24.

48. Armstrong MJ, Miyasaki JM. American Academy of Neurology. Evidencebased guideline: pharmacologic treatment of chorea in Huntington disease: report of the guideline development subcommittee of the American Academy of Neurology. Neurology. 2012;79(6):597-603.

49. Jankovic J, Clarence-Smith K. Tetrabenazine for the treatment of chorea and other hyperkinetic movement disorders. Expert Rev Neurother. 2011;11(11):1509-23.

50. Mestre T, Ferreira J, Coelho MM, Rosa M, Sampaio C. Therapeutic interventions for symptomatic treatment in Huntington's disease. Cochrane Database Syst Rev. 2009;(3):CD006456.

51. Wang H, Chen X, Li Y, Tang TS, Bezprozvanny I. Tetrabenazine is neuroprotective in Huntington's disease mice. Mol Neurodegener. 2010;5:18.

52. Andrews SC, Domínguez JF, Mercieca EC, Georgiou-Karistianis N, Stout JC. Cognitive interventions to enhance neural compensation in Huntington's disease. Neurodegener Dis Manag. 2015;5(2):155-64.

53. Frank S. Treatment of Huntington's disease. Neurotherapeutics. 2014; 11(1):153-60.

54. Mestre TA, Ferreira JJ. An evidence-based approach in the treatment of Huntington's disease. Parkinsonism Relat Disord. 2012;18(4):316-20.

55. Moulton CD, Hopkins CW, Bevan-Jones WR. Systematic review of pharmacological treatments for depressive symptoms in Huntington's disease. Mov Disord. 2014;29(12):1556-61.

56. Jamwal S, Kumar P. Antidepressants for neuroprotection in Huntington's disease: A review. Eur J Pharmacol. 2015;769:33-42.

57. Tedroff J, Waters S, Barker RA, Roos R, Squitieri F. EHDN Registry Study Group. Antidopaminergic Medication is Associated with More Rapidly Progressive Huntington's Disease. J Huntingtons Dis. 2015;4(2):131-40.

58. Beglinger LJ, Adams WH, Paulson H, Fiedorowicz JG, Langbehn DR, Duff $\mathrm{K}$, et al. Randomized controlled trial of atomoxetine for cognitive dysfunction in early Huntington disease. J Clin Psychopharmacol. 2009;29(5):484-7.

59. Cubo E, Shannon KM, Tracy D, Jaglin JA, Bernard BA, Wuu J, Leurgans SE. Effect of donepezil on motor and cognitive function in Huntington disease. Neurology. 2006;67(7):1268-71.

60. Li Y, Hai S, Zhou Y, Dong BR. Cholinesterase inhibitors for rarer dementias associated with neurological conditions. Cochrane Database Syst Rev. 2015;3:CD009444

61. Ondo WG, Mejia NI, Hunter CB. A pilot study of the clinical efficacy and safety of memantine for Huntington's disease. Parkinsonism Relat Disord. 2007;13(7):453-4.

62. Sešok S, Bolle N, Kobal J, Bucik V, Vodušek DB. Cognitive function in early clinical phase huntington disease after rivastigmine treatment. Psychiatr Danub. 2014;26(3):239-48.

63. Huntington Study Group Reach2HD Investigators. Safety, tolerability, and efficacy of PBT2 in Huntington's disease: a phase 2, randomised, double-blind, placebo-controlled trial. Lancet Neurol. 2015;14(1):39-47. 